\title{
Functional differentiation in the language network revealed by lesion-symptom mapping
}

\author{
Short title: Functional Differentiation in the Language Network \\ William Matchin ${ }^{1 *}$, Alexandra Basilakos ${ }^{1}$, Dirk-Bart den Ouden ${ }^{1}$, Brielle C. Stark ${ }^{2}$, Gregory \\ Hickok $^{3}, \&$ Julius Fridriksson ${ }^{1}$
}

${ }^{1}$ Dept. of Communication sciences and Disorders, University of South Carolina

${ }^{2}$ Dept. of Speech and Hearing Sciences, Program in Neuroscience, Indiana University Bloomington

${ }^{3}$ Dept. of Cognitive Sciences, Dept. of Language Science, University of California, Irvine

*Corresponding author

915 Greene St., Discovery 1, Room 202D, Columbia, SC 29208, USA

Email: matchin@mailbox.sc.edu

Tel: +1 803-777-9240

\section{Abstract}

Theories of language organization in the brain commonly posit that different regions underlie distinct linguistic mechanisms. However, such theories have been criticized on the grounds that many neuroimaging studies of language processing find similar effects across regions. Moreover, condition by region interaction effects, which provide the strongest evidence of functional differentiation between regions, have rarely been offered in support of these theories. Here we address this by using lesion-symptom mapping in two large, partially-overlapping groups of aphasia patients with left hemisphere brain damage due to stroke $(\mathrm{N}=121, \mathrm{~N}=92)$. We identified multiple measure by region interaction effects, associating damage to the posterior middle temporal gyrus with syntactic comprehension deficits, damage to posterior inferior frontal gyrus with expressive agrammatism, and damage to inferior angular gyrus with semantic category word fluency deficits. Our results are inconsistent with recent hypotheses that regions of the language network are undifferentiated with respect to high-level linguistic processing.

\section{Introduction}

Language is a multifaceted system consisting of interacting components. Beyond the phonetic and phonological levels, it consists of a set of lexical items (roughly words and morphemes), with associated conceptual representations, hierarchical syntactic structures, and complex semantic interpretation of these elements. Many authors have sought to associate these distinct aspects of language with different perisylvian brain regions thought to underlie language, often 
bioRxiv preprint doi: https://doi.org/10.1101/2020.07.17.209262; this version posted April 21, 2021. The copyright holder for this preprint (which

was not certified by peer review) is the author/funder, who has granted bioRxiv a license to display the preprint in perpetuity. It is made available under aCC-BY-NC-ND 4.0 International license.

Functional Differentiation in the Language Network

(but not always) supported primarily by neuroimaging data (Bornkessel-Schlesewsky \& Schlesewsky, 2013; Friederici, 2017; Hagoort, 2014; Tyler \& Marslen-Wilson, 2008; cf. Matchin $\&$ Hickok, 2020). However, the fact that a given neuroimaging study may find significant activations in some regions and not in others does not prove a functional distinction among them. In any given study, statistical power may be stronger in some regions rather than others. Therefore, region by condition interaction effects are necessary in order to conclusively demonstrate a functional distinction among regions (Nieuwenhuis et al., 2011). Such interactions have rarely been shown, limiting the ability to claim strong differences in function among regions (for discussion, see Blank et al., 2016; Blank \& Fedorenko, 2020; Fedorenko et al., 2020; cf. Matchin \& Wood, 2020). Moreover, many neuroimaging experiments have actually shown similar activations in language-related cortex for different aspects of linguistic processing (Diachek et al., 2020; Fedorenko, Nieto-Castañon, et al., 2012; Fedorenko et al., 2020; Humphries et al., 2006, 2007; Matchin et al., 2017, 2019).

In response to this lack of conclusive evidence, some researchers have questioned whether there is in fact functional segregation across regions of the language network involved in lexical access, syntactic processing, and semantic interpretation, instead advocating for a shared processing mechanism ( Blank et al., 2016, p. 201; Fedorenko et al., 2020; Fedorenko, NietoCastañón, et al., 2012; Fedorenko \& Blank, 2020; Mollica et al., 2020). This idea takes inspiration from linguistic theories that posit a close interconnection among these systems (Bresnan, 2001; Chomsky, 1995; Frank, 2002; Goldberg, 1995, 2003; Heim \& Kratzer, 1998; Jackendoff, 2002; Joshi \& Schabes, 1997; Pollard \& Sag, 1994). However, the fact that regions of the language network often show a somewhat similar activation profile in neuroimaging experiments does not distinguish between a neural architecture with the same functional mechanism across regions and a neural architecture with tightly interconnected yet distinct mechanisms across regions. This is because lexical, syntactic, and semantic components of language are systematically connected. For example, inverting the order of words in a sentence like dog bites man results in a far more surprising semantic interpretation than the original. Thus, any experimental manipulation of one component is likely to affect another component, resulting in similar neuroimaging effects across regions, despite the possibility that these regions in fact underlie distinct mechanisms.

This tight connection between components of language poses an obstacle to identifying the potentially distinct brain bases of higher-level linguistic functions through the use of neuroimaging. Lesion-symptom mapping (LSM), the study of associations between brain damage and behavioral deficits, can help resolve this conundrum. Lesion-symptom mapping allows a researcher to identify brain regions necessarily involved in a particular linguistic function, rather than functional neuroimaging in healthy individuals, which only provides correlative information (Bates et al., 2003; Rorden \& Karnath, 2004; Wilson, 2017). Previous lesion-symptom mapping studies have associated different language-related brain regions with different linguistic processes (J. Ding et al., 2020; Dronkers et al., 2004; Gleichgerrcht et al., 2016; Kristinsson et al., 2020; Magnusdottir et al., 2013; Matchin et al., 2020; Mesulam et al., 2015; Pillay et al., 2017; Riccardi et al., 2020; Rogalsky et al., 2018; Schwartz et al., 2011; Thothathiri et al., 2012; Wilson, Henry, et al., 2010; Wilson, Dronkers, et al., 2010). However, it could be the case that anatomical or other forms of variability could result in a significant lesion-deficit association in one area and a subthreshold association in another, but this does not mean that the first region is 
bioRxiv preprint doi: https://doi.org/10.1101/2020.07.17.209262; this version posted April 21, 2021. The copyright holder for this preprint (which

was not certified by peer review) is the author/funder, who has granted bioRxiv a license to display the preprint in perpetuity. It is made available under aCC-BY-NC-ND 4.0 International license.

Functional Differentiation in the Language Network

significantly more implicated in such deficits than the second. As with functional neuroimaging, region by condition interaction effects are necessary to show that some region is more strongly implicated in a given task than another region, but none of these previous studies report task by region interaction effects. Therefore, while it is plausible that different regions process different aspects of language, it has not yet been conclusively shown using region by condition interaction analyses, which directly compare the strength of effects between regions.

In order to address this issue, we assessed three measures tapping into distinct linguistic processes: syntactic comprehension, expressive agrammatism, and semantic category word fluency, in a LSM study with two partially overlapping cohorts of people with chronic left hemisphere damage following stroke $(\mathrm{N}=121$ and $\mathrm{N}=92)$. We hypothesized that we would find significant measure by region interaction effects, supporting theories of language organization in the brain that posit distinct linguistic mechanisms in different regions of the language network, as opposed to theories that posit that these regions share a common mechanism.

\section{$2 \quad$ Materials \& Methods}

\section{$2.1 \quad$ Subjects \& Measures}

In two partially overlapping groups of subjects, we assessed three different measures: (i) syntactic comprehension (Group 1, N=121), (ii) expressive agrammatism (Group 2, N=92), and (iii) semantic category word fluency (Group 2, N=92). Subjects were assessed on a number of language batteries, which were part of multiple studies on aphasia recovery. Group 1 subjects were the same as reported in Den Ouden et al. (2019) and Kristinsson et al. (2020). 47 subjects were included solely in Den Ouden et al. (2019), 48 subjects were included solely in Kristinsson et al. (2020), and 26 subjects were included in both studies. Group 2 subjects were the same as reported in Den Ouden et al., (2019) and Matchin et al., (2020). 39 subjects were included solely in Den Ouden et al. (2019), 32 were included solely in Matchin et al. (2020), and 21 subjects were included in both studies (for the 21 subjects that were included in both studies, we used the ratings in Matchin et al., 2020). All of the lesion maps and behavioral data for subjects enrolled in this study are available for download at https://www.dropbox.com/sh/3w4aeizgypfs $7 \mathrm{sd} / \mathrm{AAB}-$ W8Yn5qDUFeBj90WKsBqAa?dl=0.

We derived the syntactic comprehension measure from two different sentence-picture matching tasks reported in more detail elsewhere (Den Ouden et al., 2019; Kristinsson et al., 2020), with lesion data for subjects included here partially reported in Den Ouden et al. (2019) and Fridriksson et al. (2018). The tasks involved a range of constructions, but our focus here is on complex, semantically reversible sentences with non-canonical word order. These included object-extracted clefts (Kristinsson et al., 2020; e.g., it is the boy that the cat chases), objectextracted relative clauses (Den Ouden et al., 2019; e.g., the boy that the girl chased is happy), and object-extracted Wh-questions (both studies; e.g. which boy did the girl chase?). Sentences of this sort have a long history in research on syntactic ability in comprehension because (i) lacking canonical English subject-verb-object word order and (ii) lacking semantic plausibility constraints (c.f., which apple did the boy eat?), they require syntactic analysis for determining who is doing what to whom (Caramazza \& Zurif, 1976). Performance on such sentences is often compared to comprehension of simple active-voice sentences (i.e., the noun verbed the noun) as 
bioRxiv preprint doi: https://doi.org/10.1101/2020.07.17.209262; this version posted April 21, 2021. The copyright holder for this preprint (which

was not certified by peer review) is the author/funder, who has granted bioRxiv a license to display the preprint in perpetuity. It is made available under aCC-BY-NC-ND 4.0 International license.

Functional Differentiation in the Language Network

a control for speech perception, lexical processing, basic ability to infer an event structured based on a sequence of words, and working memory or decision-making resources involved in performing a sentence-picture matching task. Thus, our syntactic comprehension measure was computed as the average performance on complex sentences with performance on simple, semantically reversible active sentences covaried out using linear regression. For subjects who performed both studies $(\mathrm{N}=26)$, in order to provide the most reliable estimate, scores were averaged across the two studies, which contained the same number of trials ( 5 trials per sentence type).

We derived the expressive agrammatism measure from samples of connected speech production elicited either by (i) describing the Cookie Theft picture (Goodglass \& Kaplan, 1983, as reported in Den Ouden et al., 2019) or (ii) retelling the story of Cinderella in their own words (MacWhinney et al., 2011, as reported in Matchin et al., 2020). The presence of expressive agrammatism was determined as described in Matchin et al., (2020). Briefly, production samples were rated independently by speech and language experts for the systematic simplification of sentence structure and omission of function words and morphemes. This resulted in a categorical assessment for each subject, either agrammatic or not. We included speech rate as a covariate using logistic regression (words per minute during the task) in order to focus on residual morphosyntactic sequencing abilities rather than general motor speech abilities.

The semantic category word fluency measure came from the Word Fluency subtest of the Western Aphasia Battery - Revised (WAB-R) (Kertesz, 2007), as administered by a licensed speech language pathologist. The Word Fluency subtest involves asking the subject to name as many animals as possible within one minute (maximum score is 20). Word fluency is designed to assess two broad categories of abilities: access to conceptual-semantic representations and executive function (Chertkow \& Bub, 1990; Troyer et al., 1997; Unsworth et al., 2011). However, Whiteside et al. (2016) performed a factor analysis of a highly similar semantic category word fluency task and found that deficits on this task were associated with language measures but not executive function measures. In addition, a previous lesion-symptom mapping study by Baldo et al. (2006) found that deficits in a similar semantic category word fluency task were associated with temporal and inferior parietal damage but not frontal damage, whereas letter fluency was associated with frontal and anterior parietal damage (see Libon et al., 2009 for similar findings). These results suggest that semantic word fluency tasks, at least for tasks with broad semantic categories like animals, load highly on semantic processing and less highly on executive function, consistent with the fact that patients with semantic dementia perform worse on semantic category fluency measures than letter fluency relative to patients with Alzheimer's disease (Marczinski \& Kertesz, 2006). However, some of the variance in the word fluency task is likely due to articulatory fluency, therefore we incorporated the same speech rate covariate we used for the expressive agrammatism analysis.

All subjects were recruited through local advertisement. They provided informed consent to participate in this study, which was approved by the Institutional Review Boards at the University of South Carolina and the Medical University of South Carolina. All subjects had at least one ischemic stroke to the left hemisphere at least six months prior to study inclusion and were also pre-morbidly right handed (self- disclosed). Demographic information for the two groups of subjects is shown in Table 1. 
Functional Differentiation in the Language Network

\begin{tabular}{|c|c|c|}
\hline & Group 1 & Group 2 \\
\hline Measures & $\begin{array}{l}\text { Syntactic } \\
\text { Comprehension }\end{array}$ & $\begin{array}{l}\text { Semantic Category } \\
\text { Word Fluency } \\
\text { Expressive } \\
\text { Agrammatism }\end{array}$ \\
\hline $\begin{array}{l}\text { Total number of } \\
\text { subjects }\end{array}$ & $\mathrm{N}=121$ & $\mathrm{~N}=92$ \\
\hline Sex & 79 male, 42 female & 60 male, 32 female \\
\hline $\begin{array}{l}\text { Mean age at } \\
\text { testing (years) }\end{array}$ & $59.6(\mathrm{SD}=10.6)$ & $58.7(\mathrm{SD}=11.1)$ \\
\hline $\begin{array}{l}\text { Mean months post- } \\
\text { first stroke at } \\
\text { initial testing }\end{array}$ & $47.5(\mathrm{SD}=52.4)$ & $46.4(\mathrm{SD}=49.6)$ \\
\hline $\begin{array}{l}\text { Mean number of } \\
\text { strokes }\end{array}$ & $1.17(\mathrm{SD}=0.49)$ & $1.11(\mathrm{SD}=0.43)$ \\
\hline $\begin{array}{l}\text { Mean education } \\
\text { (years) }\end{array}$ & $15.4(\mathrm{SD}=2.3)$ & $15.3(\mathrm{SD}=2.3)$ \\
\hline $\begin{array}{l}\text { Mean lesion } \\
\text { volume }\left(\mathrm{mm}^{3}\right)\end{array}$ & $\begin{array}{l}112,652(\mathrm{SD}= \\
94,945)\end{array}$ & $96,175(\mathrm{SD}=84,514)$ \\
\hline Mean $W A B-R A Q$ & $66(\mathrm{SD}=26.9)$ & $75.8(\mathrm{SD}=19.9)$ \\
\hline
\end{tabular}

Table 1 . Subject information for the two partially overlapping groups of subjects. SD = standard deviation. $\mathrm{AQ}=$ aphasia quotient, a summary measure of overall language ability.

\subsection{Brain Imaging \& Lesion mapping}

We acquired anatomical MRIs and performed lesion mapping using the same parameters and procedures as described in Fridriksson et al. (2018). Neuroimaging data were collected at the University of South Carolina and the Medical University of South Carolina. Lesions were demarcated onto each subject's T2 image by an expert technician or an expert neurologist blind to the behavioral data.

Lesion overlap maps for both groups are shown in Figure 1 (a \& b). Overall, there was good coverage in perisylvian cortex, covering all selected regions of interest (described below).

\subsection{Region of Interest (ROI) definition}

Rather than using structurally-defined ROIs, which may not line up precisely with linguisticallyrelevant regions of the brain of interest in the present study, we used the statistical maps associated with a previous fMRI study on sentence processing (Matchin et al., 2017) to define ROIs for anlaysis. This study compared multiple conditions, including full natural sentences (e.g., the poet might recite a verse) and jabberwocky sentences, which involve the substitution of pseudowords for content words (e.g., the tevill will sawl a pand). The contrast of natural sentences > jabberwocky sentences highlighted a number of language-related brain regions in association cortex that are frequently identified in brain imaging studies of syntax and semantics. 
Functional Differentiation in the Language Network

We therefore used this contrast with a reduced voxel-wise threshold of $p<0.01$ (Figure 1c). We selected clusters corresponding to four left hemisphere regions that have been previously implicated in higher-level linguistic processing (Figure 1d), including most prominently syntax and semantics: the inferior angular gyrus (iAG), the posterior middle temporal gyrus (pMTG), the anterior superior temporal sulcus (aSTS), and the posterior inferior frontal gyrus (pIFG). Several of the clusters revealed by the analysis were contiguous at local minima, and so we manually separated them at these junctures to form four separate ROIs.

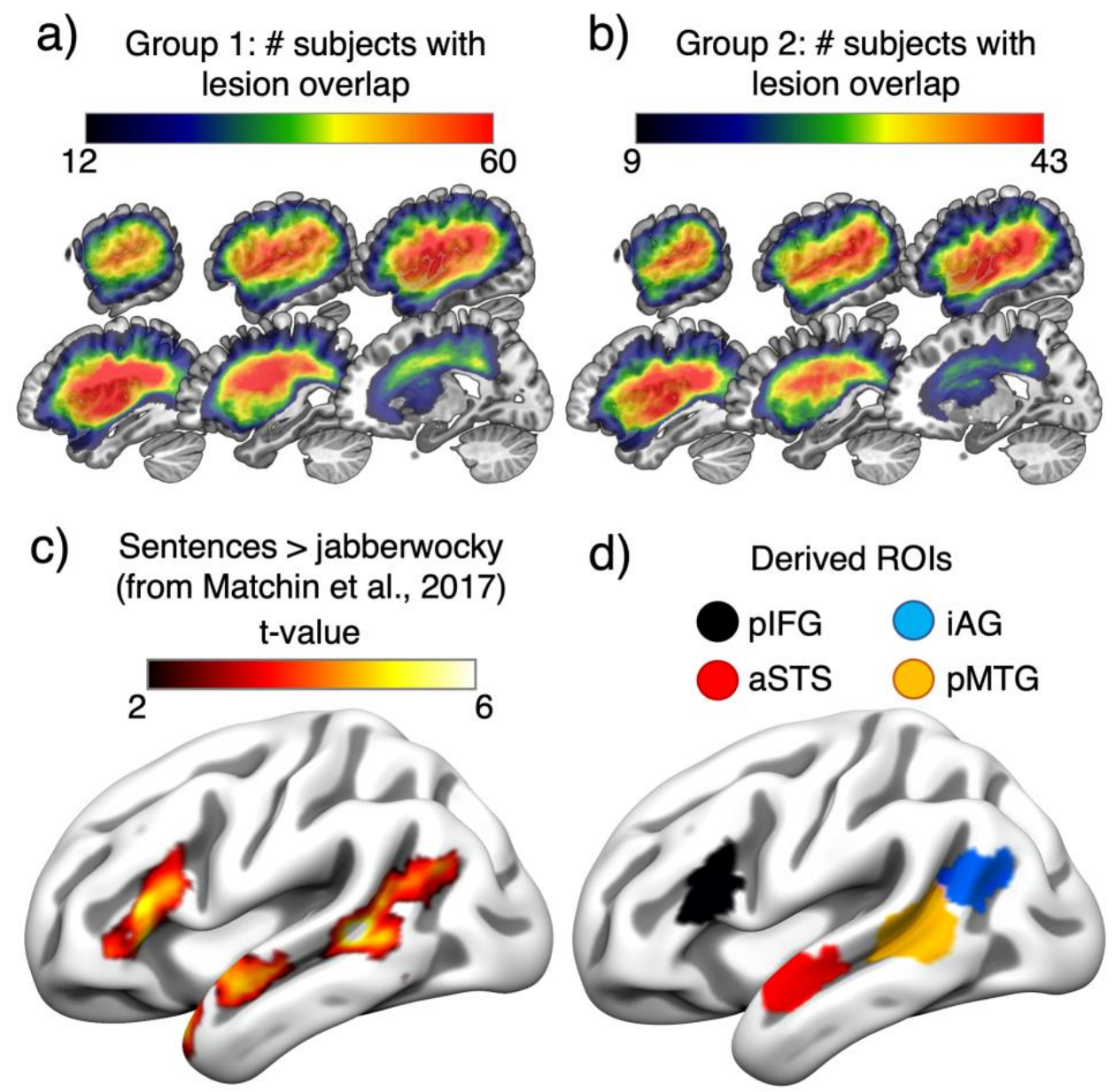

Figure 1. (a) Lesion overlap map for the Group $1(\mathrm{~N}=121)$, assessed for Syntactic

Comprehension. The lower boundary of 12 corresponds to voxels where at least $10 \%$ of subjects had damage. (b) Lesion overlap map for Group 2 group $(\mathrm{N}=92)$, assessed for Semantic Category Word Fluency and Expressive Agrammatism. The lower boundary of 9 corresponds to voxels where at least $10 \%$ of subjects had damage. (c) Statistical contrast of natural sentences > jabberwocky sentences from Matchin et al., (2017) at the uncorrected voxel-wise threshold of $\mathrm{p}$ $<0.01$. (d) Selected ROIs using the clusters derived from the contrast of natural sentences > jabberwocky sentences from Matchin et al., (2017). Blue: inferior angular gyrus (iAG); orange: posterior middle temporal gyrus (pMTG); red: anterior superior temporal sulcus (aSTS); black: posterior inferior frontal gyrus (pIFG).

\subsection{Lesion Analyses}


bioRxiv preprint doi: https://doi.org/10.1101/2020.07.17.209262; this version posted April 21, 2021. The copyright holder for this preprint (which

was not certified by peer review) is the author/funder, who has granted bioRxiv a license to display the preprint in perpetuity. It is made available under aCC-BY-NC-ND 4.0 International license.

Functional Differentiation in the Language Network

In order to assess the overall relationship between our behavioral measures and damage to language-relevant regions, we performed ROI-based univariate and multivariate regression analyses in NiiStat (https://www.nitrc.org/projects/niistat/) using the set of four ROIs we derived from Matchin et al. (2017). Some authors have pointed out the spatial distortion in univariate lesion-symptom mapping analyses that occurs based on the non-random distribution of lesions in the brain and the potential superiority of multivariate methods in reducing this distortions (Mah et al., 2014). However, Ivanova et al. (2021) pointed out that these comparisons involved outdated and procedures for univariate analyses. They performed a systematic comparison of univariate and multivariate approaches to lesion-symptom mapping, incorporating crucial features that were absent from Mah et al. (2014): permutation testing for multiple comparisons, lesion volume as a covariate, and minimum 5-10\% lesion load threshold. Ivanova et al. (2021) found that, with these updated procedures, univariate methods actually outperformed multivariate methods on most dimensions related to spatial distortion. They recommend reporting both univariate and multivariate analyses incorporating these crucial procedures. We accordingly corrected for multiple comparisons using permutation tests (10,000 permutations), with a minimum lesion load of $10 \%$ of sample, and all analyses incorporated lesion volume as a covariate, as also recommended by DeMarco \& Turkeltaub (2018). We supplement these results with unthresholded univariate voxel-wise lesion maps associated with each measure in order to illustrate that our ROI analyses did not obscure the lesion distribution associated with each measure, in a similar fashion as is recommended for fMRI analyses (Poldrack et al., 2008).

We also performed three hypothesis-driven interaction analyses, one for each measure. With respect to syntactic comprehension, we tested the interaction between the pMTG and pIFG. Both the pIFG and pMTG are commonly activated in neuroimaging studies of syntactic comprehension. While most theoretical models of syntax posit a key role for the pIFG in receptive syntax (Friederici, 2017; Hagoort, 2014; Tyler \& Marslen-Wilson, 2008), previous lesion-symptom mapping studies have indicated that damage to posterior temporal areas (but not frontal areas) is critically implicated in syntactic comprehension deficits (Kristinsson et al., 2020; Pillay et al., 2017; Corianne Rogalsky et al., 2018). In this light, the models proposed by Matchin \& Hickok (2020) and Bornkessel-Schlesewsky \& Schlesewsky (2013) posit that the pIFG is not critically involved in syntactic comprehension. Therefore, we hypothesized that damage to the pMTG would be significantly more implicated in syntactic comprehension deficits than damage to the pIFG.

Most theoretical models of syntax in the brain attribute a key role in syntactic production to the pIFG but not the aSTS (Friederici, 2017; Hagoort, 2014; Matchin \& Hickok, 2020; Tyler \& Marslen-Wilson, 2008). Consistent with this, agrammatism is primarily associated with damage to inferior frontal cortex, and to a lesser extent posterior temporal-parietal cortex, but not anterior temporal cortex (Sapolsky et al., 2010; Wilson et al., 2010; Den Ouden et al., 2019; Matchin et al., 2020). Therefore, with respect to our expressive agrammatism measure, we tested the interaction between aSTS and pIFG. We expected that our measure would be significantly more associated with damage to pIFG than aSTS.

Finally, with respect to semantic category word fluency, we tested the interaction between iAG and pIFG. Although damage to both of these regions has been claimed to be generally implicated 
bioRxiv preprint doi: https://doi.org/10.1101/2020.07.17.209262; this version posted April 21, 2021. The copyright holder for this preprint (which

was not certified by peer review) is the author/funder, who has granted bioRxiv a license to display the preprint in perpetuity. It is made available under aCC-BY-NC-ND 4.0 International license.

Functional Differentiation in the Language Network

in lexical-semantic deficits (Fedorenko et al., 2020), damage to iAG and surrounding temporal cortex, but not frontal cortex, was previously shown to be associated with deficits on a similar word fluency measure (Baldo et al., 2006). Consistent with this, most theories attribute a (morpho-)syntactic function to the pIFG (Friederici, 2017; Hagoort, 2014; Matchin \& Hickok, 2020; Tyler \& Marslen-Wilson, 2008), or a top-down selection mechanism (Novick et al., 2005; Thompson-Schill \& Cutler, 2005), but not a basic lexical or conceptual-semantic function. Therefore, we expected that damage to iAG would be significantly more associated with impairments on this measure than damage to pIFG.

To test these interactions, we first calculated proportion damage to each ROI and adjusted the data using a rationalized arcsine transform (Studebaker, 1985), and then computed residual damage values by covarying out the effect of lesion volume. We then assessed the region by measure interaction effect in linear regression for each of the three measures of interest in SPSS. We corrected for multiple comparisons using a Bonferroni correction with an adjusted alpha threshold of $p<0.0167$ for each of the three independent comparisons, controlling the total error at $\mathrm{p}<0.05$.

\section{Results}

The univariate ROI analyses, corrected for multiple comparisons (FWE p < 0.05), revealed the following effects:

- Syntactic comprehension: two ROIs showed a significant negative association between percent damage and behavioral scores, pMTG $(Z=-3.13)$ and aSTS $(Z=-2.46)$.

- Semantic category word fluency: one ROI showed a significant negative association between percent damage and behavioral scores, iAG $(Z=-3.91)$.

- Expressive agrammatism: one ROI showed a significant positive association between percent damage and behavioral scores, pIFG $(Z=3.10)$. I.e., subjects who had stronger expressive agrammatism scores were more likely to have damage to pIFG.

The multivariate ROI analyses, corrected for multiple comparisons (FWE $\mathrm{p}<0.05$ ), revealed the following effects:

- Syntactic comprehension: two ROIs showed a significant negative association between percent damage and behavioral scores, pMTG $(Z=-2.07)$ and aSTS $(Z=-1.95)$.

- Semantic category word fluency: one ROI showed a significant negative association between percent damage and behavioral scores, iAG $(Z=-2.20)$.

- Expressive agrammatism: no ROI showed a significant positive association between percent damage and behavioral scores.

Unthresholded univariate voxel-wise maps support the localization of the effects revealed by the ROI analyses, (Figure 2), although the strongest effect of expressive agrammatism was in the posterior inferior frontal sulcus/middle frontal gyrus rather than the IFG itself. 


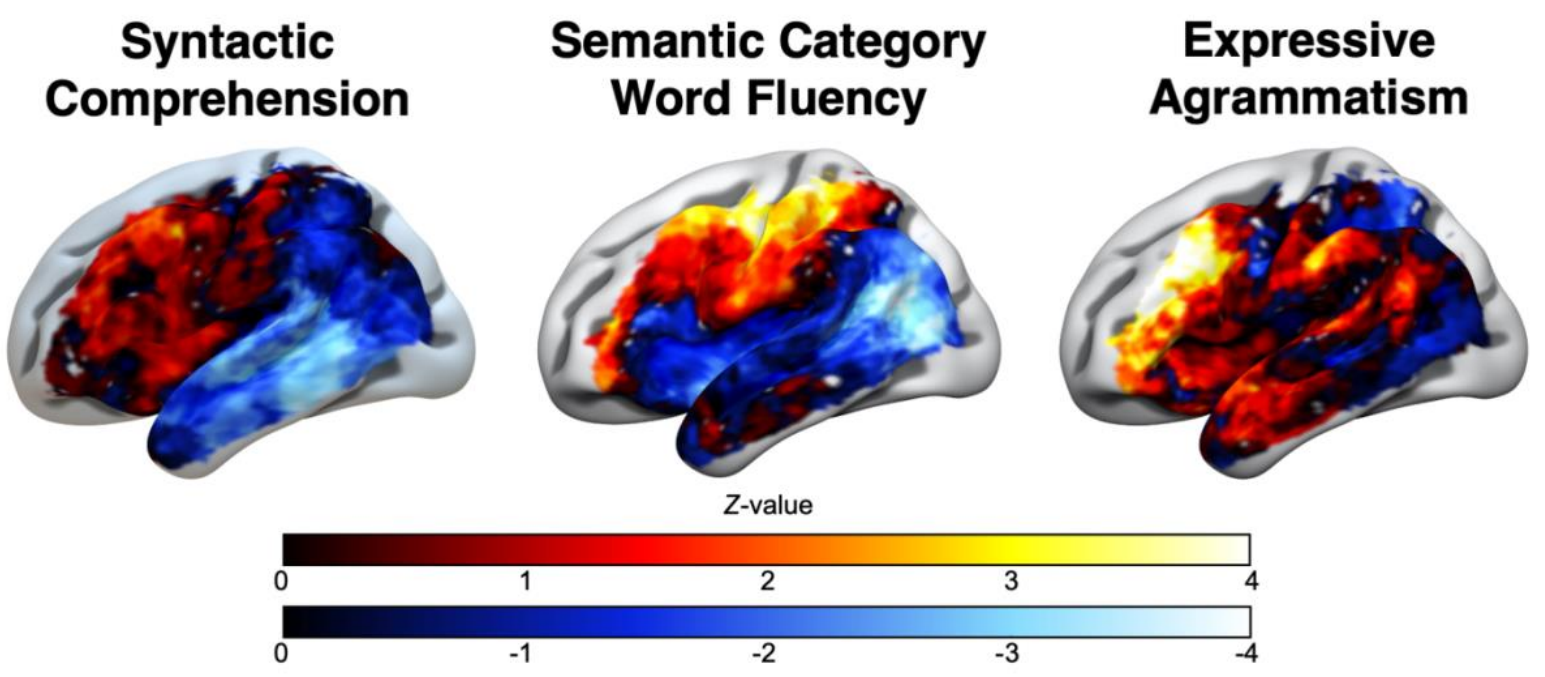

Figure 2. Unthresholded voxel-wise univariate analyses for each of the three behavioral measures: Syntactic Comprehension (noncanonical sentence comprehension performance with active sentence comprehension as a covariate), Semantic Category Word Fluency (WAB word fluency with speech rate as a covariate), and Expressive Agrammatism (perceptual agrammatism ratings with speech rate as a covariate). Each measure is identified at top in bold, corresponding to all of the figures underneath.

Scatterplots illustrating the region by measure interactions we tested are shown in Figure 3. Cohen (1988) recommends interpreting effect sizes $\left(\eta^{2}\right)$ with the following benchmarks: $0.01=$ small; $0.06=$ medium; $0.14=$ large.

- Syntactic Comprehension: the association between deficits on this measure with damage to the pMTG was significantly stronger than with damage to the pIFG, $F(1,119)=9.013$, $p=0.003, \eta^{2}=0.076$.

- Semantic Category Word Fluency: the association between deficits on this measure with damage to the iAG was marginally significantly stronger than with damage to the pIFG, $\mathrm{F}(1,90)=5.294, p=0.024, \eta^{2}=0.040$.

- Expressive Agrammatism: the association between positive assessment on this measure with damage to the pIFG was marginally significantly stronger than with damage to the aSTS, $\mathrm{F}(1,90)=4.432, p=0.038, \eta^{2}=0.023$. I.e., subjects who had stronger expressive agrammatism scores were more likely to have damage to pIFG than to aSTS. 


\section{Syntactic Comprehension}

\section{Semantic Category Word Fluency}

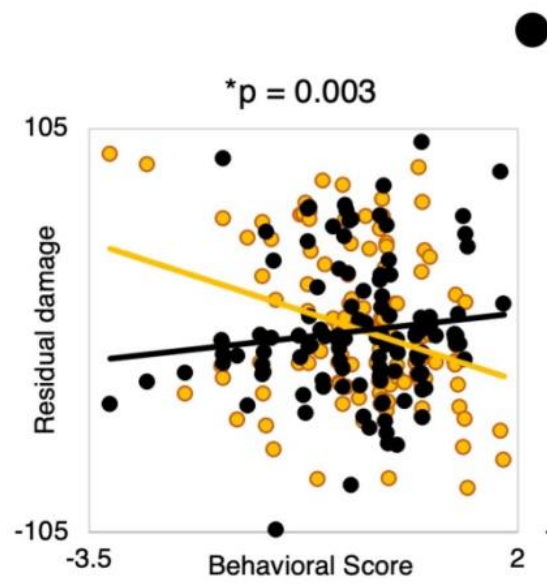

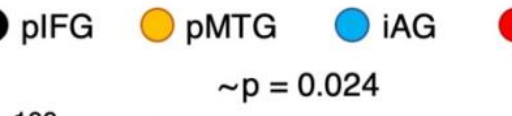

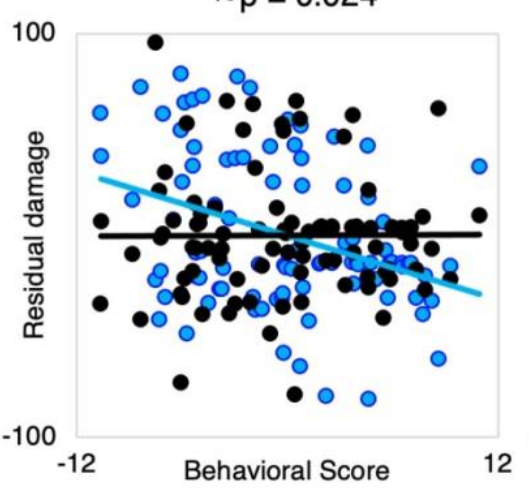

\section{Expressive Agrammatism} aSTS

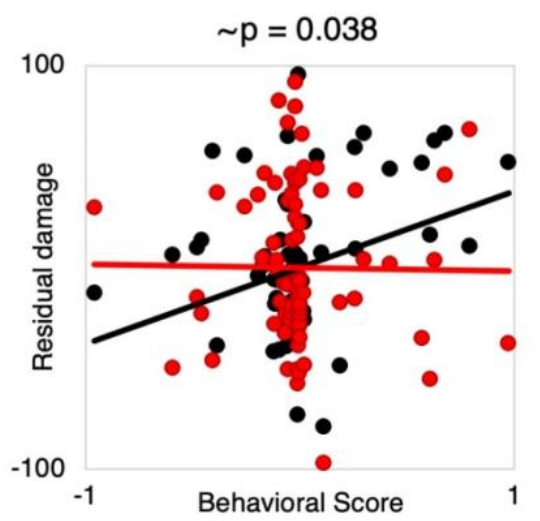

Figure 3. Scatter plots illustrating three hypothesis-driven region by measure interaction analyses, corrected for multiple comparisons using a Bonferroni correction (individual $\mathrm{p}<$ 0.0167), for the four ROIs of interest (pIFG, pMTG, iAG, aSTS) and the three behavioral measures: Syntactic Comprehension (noncanonical sentence comprehension performance with active sentence comprehension as a covariate), Semantic Category Word Fluency (WAB word fluency with speech rate as a covariate), and Expressive Agrammatism (perceptual agrammatism ratings with speech rate as a covariate). Residual damage indicates the residual percent damage values within an ROI, with lesion volume as a covariate. Straight lines indicate linear trends. pMTG = posterior middle temporal gyrus; $\mathrm{pIFG}=$ posterior inferior frontal gyrus; $\mathrm{iAG}=$ inferior angular gyrus; aSTS $=$ anterior superior temporal sulcus. $*$ significant effect. $\sim$ effect approaching significance.

\section{Discussion}

In this lesion-symptom mapping (LSM) study in two groups of patients with chronic post-stroke aphasia $(\mathrm{N}=121, \mathrm{~N}=92)$, deficits in three distinct measures of linguistic processing were each associated with damage to distinct regions of the language network: syntactic comprehension was associated primarily with pMTG damage and secondarily with aSTS damage, semantic category word fluency was associated with iAG damage, and expressive agrammatism was associated with pIFG damage. None of these effects are unique to our study, supporting similar previous findings in the literature, as we discuss below. However, critically, we also showed region by measure interaction effects, such that damage to specific regions in the language network was more associated with each behavioral measure than damage to other regions, significantly or trending toward significance.

Combined, these results narrow down possible functions of these brain regions in higher-level linguistic processing, and suggest that neuroimaging research needs to incorporate insights from lesion symptom mapping in order to understand the architecture of language in the brain. Namely, the region by measure interactions we identified present strong challenges to the hypothesis that language-related brain regions underlie a similar function with respect to 
bioRxiv preprint doi: https://doi.org/10.1101/2020.07.17.209262; this version posted April 21, 2021. The copyright holder for this preprint (which

was not certified by peer review) is the author/funder, who has granted bioRxiv a license to display the preprint in perpetuity. It is made available under aCC-BY-NC-ND 4.0 International license.

Functional Differentiation in the Language Network

linguistic processing, a hypothesis that has been advocated most recently in light of neuroimaging data alone (Blank et al., 2016; Caplan et al., 1996; Dick et al., 2001; Fedorenko et al., 2020; Fedorenko \& Blank, 2020; Mollica et al., 2020). Our results are instead broadly consistent with neuroanatomical models that posit distinct linguistic functions to different regions within the language network (Bornkessel-Schlesewsky \& Schlesewsky, 2013; Friederici, 2017; Hagoort, 2014; Matchin \& Hickok, 2020; Tyler \& Marslen-Wilson, 2008). However, the model presented by Matchin \& Hickok (2020) provides explanations for all of the identified effects and interactions, whereas the other models fail to provide clear explanations for one or more of them. We discuss each of these measures in turn with respect to existing lesion-symptom mapping literature and how these findings relate to existing models of language organization in the brain.

\subsection{Expressive agrammatism}

The association between the classical, production-related deficit of agrammatism and damage to inferior frontal cortex has a long history stemming back to the origins of aphasiology (Kleist, 1914; Kussmaul, 1877; Pick, 1913; Tissot et al., 1973), supported by recent LSM studies (Sapolsky et al., 2010; Wilson et al., 2010; Den Ouden et al., 2019; Matchin et al., 2020). Our results, combining data from two previously reported studies (Den Ouden et al., 2019; Matchin et al., 2020), reaffirm this association. The anterior temporal lobe (ATL) more broadly has been associated with syntax (i.e., comprehension of sentences or phrases vs. word lists) in many neuroimaging studies (Bemis \& Pylkkanen, 2011; J. Brennan et al., 2012; J. R. Brennan et al., 2016; Humphries et al., 2005, 2006; Mazoyer et al., 1993; C. Rogalsky et al., 2011; C. Rogalsky $\&$ Hickok, 2009). However, previous research on patients with ATL damage and/or degeneration shows no evidence of agrammatic production deficits (Hodges et al., 1992; Hodges \& Patterson, 2007; Kho et al., 2008; Mesulam et al., 2015; Corianne Rogalsky et al., 2018; see Wilson et al., 2014 for data and a review). Our study supports the general picture painted by previous lesionsymptom mapping studies in showing that the association of expressive agrammatism with pIFG damage was stronger than with aSTS damage, trending toward significance.

This suggests the existence of some syntactic mechanism involved in sentence production associated specifically with the pIFG but not the aSTS. While most theories of language organization in the brain posit a syntactic mechanism in inferior frontal cortex (Friederici, 2017; Hagoort, 2014; Matchin \& Hickok, 2020; Tyler \& Marslen-Wilson, 2008), the theory proposed by Bornkessel-Schlesewsky \& Schlesewsky (2013) does not, suggesting that the pIFG supports linguistiuc processing through a more general cognitive control function. However, this theory attributes syntactic processing to a dorsal stream spanning posterior temporal cortex through parietal and frontal cortex. On this point, the fact that our analysis only approached significance $(\mathrm{p}=0.038$, corrected threshold $\mathrm{p}<0.0167)$ may be due to the fact that the posterior middle frontal cortex and not pIFG was most strongly associated with expressive agrammatism. Future research should further investigate the role of middle frontal regions in linguistic processing.

\subsection{Syntactic comprehension}

We found that damage to the pMTG was significantly more associated with syntactic comprehension deficits compared to the pIFG, which was not implicated at all. Previous LSM 
bioRxiv preprint doi: https://doi.org/10.1101/2020.07.17.209262; this version posted April 21, 2021. The copyright holder for this preprint (which

was not certified by peer review) is the author/funder, who has granted bioRxiv a license to display the preprint in perpetuity. It is made available under aCC-BY-NC-ND 4.0 International license.

Functional Differentiation in the Language Network

studies have found an association between residual syntactic comprehension scores (regressing out single word comprehension or production) with damage to the posterior temporal lobe but not the pIFG (Kristinsson et al., 2020; Pillay et al., 2017; Corianne Rogalsky et al., 2018). Our results reinforce these previous studies by showing that the effect in pMTG is statistically stronger than in pIFG (in fact, the pIFG showed an effect numerically in the opposite direction). As with expressive agrammatism, this result is incompatible with the shared mechanism view of the language network. Most models of language organization in the brain posit that the pIFG is not only critical for processing hierarchical structure in production but also comprehension (Friederici, 2017; Hagoort, 2014; Tyler \& Marslen-Wilson, 2008). However, the data are more consistent with the proposals of Matchin \& Hickok (2020) and Bornkessel-Schlesewsky \& Schlesewsky (2013), who argue instead that the pIFG's role in sentence comprehension is restricted to a supporting mechanism, but not critical for building hierarchical structure.

Our univariate analyses also identified a significant, though weaker, association between syntactic comprehension deficits and damage to the aSTS. Some LSM studies have found some evidence of an association between syntactic comprehension deficits and ATL damage (Dronkers et al., 2004; Magnusdottir et al., 2013). Matchin et al. (2020) speculated that these effects might have been due to the lack of lesion volume as a control, predicting that including lesion volume might eliminate such an association. However, the analyses reported here all included lesion volume as a covariate, suggesting that syntactic comprehension deficits may be associated with anterior temporal as well as posterior temporal damage. This is somewhat similar to previous studies of syntactic comprehension deficits, which generally found more robust effects in posterior temporal cortex but some association with noncanonical sentence comprehension deficits in aSTS (Pillay et al., 2017; Rogalsky et al., 2018; Kristinsson et al., 2020). This raises the question of whether the aSTS is involved in some aspect of combinatorial processing, which may be semantic in nature (Pylkkänen, 2020). Future studies should seek to investigate possible function segregation between pMTG and aSTS along these lines. We hypothesize that semantic combination (controlling for syntax) will be more associated with aSTS damage, whereas syntactic combination (controlling for semantics) will be more associated with pMTG damage.

\subsection{Semantic category word fluency}

In our univariate analyses, damage to the $\mathrm{iAG}$ and no other region was significantly associated with deficits on the semantic category word fluency measure. Furthermore, our region by measure interaction analysis revealed that damage to the iAG was more associated with deficits than damage to the pIFG, trending towards significance. Our result is similar to Baldo et al. (2006), who found that deficits on a semantic similar word fluency task were associated with posterior temporal and inferior parietal damage but not frontal damage.

Most theories of language organization in the brain posit a role for lexical and/or conceptualsemantic processing in the iAG (Friederici, 2017; Hagoort, 2014; Tyler \& Marslen-Wilson, 2008; Matchin \& Hickok, 2020; cf. Bornkessel-Schlesewsky \& Schlesewsky, 2013). Many neuroimaging studies have indicated that this region is particularly responsive to manipulations of semantics, but not syntax (see Matchin \& Hickok, 2020 for a review). For example, Pallier et al. (2011) showed that this region responded to increased linguistic structural complexity, but not 
bioRxiv preprint doi: https://doi.org/10.1101/2020.07.17.209262; this version posted April 21, 2021. The copyright holder for this preprint (which

was not certified by peer review) is the author/funder, who has granted bioRxiv a license to display the preprint in perpetuity. It is made available under aCC-BY-NC-ND 4.0 International license.

Functional Differentiation in the Language Network

when meaningful content words were replaced with pseudowords, a finding that has been replicated multiple times (Fedorenko, Nieto-Castañon, et al., 2012; Goucha \& Friederici, 2015; Matchin et al., 2017). Similarly, Price et al. (2015) found that processing meaningful word pair combinations (e.g. "plaid jacket") results in more activity in iAG than less meaningful combinations (e.g. "moss pony"), including controls for co-occurrence frequency. Our results, an association between $\mathrm{iAG}$ damage and deficits in semantic category word fluency, are strongly consistent with this literature.

According to the view of undifferentiated higher-level linguistic processing, pIFG should have also been critically involved in lexical-conceptual retrieval as with iAG. However, our results suggest that for a word fluency task involving a relatively broad category (animals), the pIFG is not significantly implicated, and less so than the iAG. By contrast, some LSM studies of semantic errors in picture naming implicate pIFG damage, among other regions (Dell et al., 2013; Schwartz et al., 2009). However, picture naming, unlike the word fluency task, involves selecting among competing alternatives (e.g., to name a picture of a cat, the competing alternative dog must be suppressed). Interestingly, a recent LSM study of word-level semantic errors in natural, connected speech found that increased errors were associated with temporal and inferior parietal damage, but not frontal damage (Stark et al., 2019). Connected speech differs from confrontation or picture naming in allowing the subject to select alternative words or concepts, which reduces the burden of the task on selection abilities. The whole body of evidence is consistent with a role for pIFG in a selection or control mechanism that is critically involved when there is competition among items, but speaks against a role for basic retrieval of lexical items or associated concepts in frontal cortex, supported instead by temporal and inferior parietal cortex (Lambon Ralph, 2017; Lau et al., 2008; Novick et al., 2005). This selection mechanism could be domain-general (Novick et al., 2005), but subregions of pIFG that respond selectively to language (Fedorenko, Duncan, et al., 2012) could also implement a languagespecific control mechanism (Matchin, 2018).

An interesting question is why the aSTS, and the ATL more broadly, was not implicated in semantic category word fluency deficits. Both the aSTS and the iAG have been implicated in semantic processing, broadly construed, in both neuroimaging studies and lesion-symptom mapping of semantic word-naming errors (Binder et al., 2009; Fridriksson et al., 2018; Schwartz et al., 2011). Most pointedly, the degenerative syndrome known as primary progressive aphasia of the semantic subtype (PPA-S, also known as semantic dementia) is strongly associated with mostly left, but sometimes bilateral, atrophy of the ATL, with increasingly stronger deficits in conceptual knowledge and single word comprehension (Hodges et al., 1992; Hodges \& Patterson, 2007; Mesulam et al., 2013, 2015). Category fluency has also been shown to be reduced in patients of this type (Hodges \& Patterson, 1992). However, our study, as well as Baldo et al. (2006), failed to identify any hint of an effect in the aSTS or the ATL more broadly for semantic category word fluency deficits.

We suggest here that the relevant distinction is concept specificity. In the study reported by Hodges \& Patterson (1992), the PPA-S patients had reduced category fluency for more specific categories, breeds of dog and boats, requiring finer differentiation of features than animals, the broader category used here and in Baldo et al. (2006). In fact, Hodges \& Patterson (1992) showed that in a picture sorting test, PPA-S patients were able to perform broad categorizations 
Functional Differentiation in the Language Network

such as living vs. man-made quite well, in stark contrast to their picture naming and word comprehension abilities. Both picture naming and most word comprehension tasks (with picture pointing as the response) require a subject to process specific visual features and attributes of an object. The involvement of the ATL in semantic processing likely relates to specific attributes or features, particularly highlighted in certain word-level production and comprehension tasks, rather than more general ones (Rogers et al., 2006). This is supported by

magnetoencephalography studies which have showed that activation in ATL is contingent on concept specificity, e.g. greater activation for higher-specificity words like canoe relative to lower-specificity words like boat, and that combinatory effects in this area only emerge for lower-specificity words (Westerlund \& Pylkkänen, 2014; Zhang, 2015; Ziegler \& Pylkkänen, 2016). Overall, a picture has emerged by which the ATL is involved in retrieving the features of specific entities, whereas the $\mathrm{iAG}$ is involved in a broader semantic function, perhaps involving event representations (Binder \& Desai, 2011; Lewis et al., 2015; Matchin et al., 2019; Schwartz et al., 2011). By contrast, the semantic category word fluency task in the present study used a very broad category, animals, which allowed for potentially a wide array of answers without requiring the subject to discriminate highly similar concepts from each other. Thus performance on this task seemingly critically required iAG but not the aSTS. We would expect that future LSM studies of word fluency using more specific semantic categories, such as dogs, boats, etc., will reveal effects in the aSTS, and possibly the pIFG as well via a selection mechanism.

\subsection{Pitfalls of the search for functional selectivity in the language network}

Recent neuroimaging studies have shown syntactic and lexical effects distributed across regions of the language network (I. Blank et al., 2016; Fedorenko et al., 2020). Fedorenko et al. (2020) argue that this constitues evidence against the existence of brain areas that selectively process syntax, and evidence for a holistic linguistic architecture in which the lexicon, syntax, combinatorial semantics, and conceptual representations are all intertwined.

First, we strongly caution against using findings from neuroimaging techniques that capture very limited facets of neural structure and function, to inform linguistic architecture, when it is extremely unclear how the postulates of linguistic theory line up with neuroscience (Embick \& Poeppel, 2015; Poeppel, 2012; Poeppel \& Embick, 2005). Even if it were true that there is no brain region selectively engaged in syntax, or any evidence of functional distinction across regions of the language network, it does not follow that there is no independent syntactic mechanism. The coarseness of the methodologies of fMRI and lesion-symptom mapping do not allow access to many aspects of neuronal function, and a basic syntactic or combinatory mechanism could very well be implemented in subtler biological properties than dedicated chunks of cortical tissue containing thousands of neurons (N. Ding et al., 2016; Gallistel \& King, 2010; Matchin \& Hickok, 2020; Murphy, 2015).

However, the region by measure interactions we present here, in conjunction with a large historical body of research in aphasiology, lesion-symptom mapping, and functional neuroimaging, suggest that there must be at least some differentiation of function within the language network. The key question is what exactly the relevant distinctions are. For example, our results do not imply that the pMTG or pIFG are selectively engaged in syntax to the exclusion of the lexicon, or that the $\mathrm{iAG}$ is selectively involved in lexical-conceptual retrieval to 
bioRxiv preprint doi: https://doi.org/10.1101/2020.07.17.209262; this version posted April 21, 2021. The copyright holder for this preprint (which

was not certified by peer review) is the author/funder, who has granted bioRxiv a license to display the preprint in perpetuity. It is made available under aCC-BY-NC-ND 4.0 International license.

Functional Differentiation in the Language Network

the exclusion of combinatory processing of any kind. In fact, the quest for evidence of functional selectivity misses what we perceive to be the goals of the neurobiology of language: to identify the functional organization of language in the brain, regardless of the issue of specificity.

In previous work, two of us (Matchin \& Hickok, 2020) have suggested that the pMTG and pIFG implement lexical-syntactic functions, with the pMTG processing hierarchical relations stored on individual lexical items and the pIFG processing linear morpho-syntactic relations. We attributed conceptual-semantic processing to different regions, namely the iAG and aSTS. The fact that all of regions in neuroimaging studies respond to lexical experimental manipulations does not speak against these hypotheses. Rather, a contrast such as words > pseudowords is likely to tax multiple functions. For example, the words $>$ pseudowords contrast engages lexical-syntactic processing mechanisms, that is access to the stored repository of words with their associated syntactic frames, access to the meanings associated with individual lexical items, and combinatory semantics enabled by the presence of real words. The fact that all regions of the language network respond to a lexicality manipulation is therefore unsurprising, because this experimental contrast likely engages all of these functions.

Both functional neuroimaging and LSM provide opportunities to uncover the functional architecture of the language network. The evidence we presented here bolsters existing studies by revealing region by measure interaction effects that provides strong evidence of functional dissociations across regions (Nieuwenhuis et al., 2011). Future studies aiming to identify further functional dissociations should develop subtler experimental measures beyond relatively course measures such as comprehension of sentences vs. word lists that are capable of distinguishing among possible underlying functions, and should test region by measure interactions if possible.

\subsection{Limitations of the present work}

The biggest limitation of the present work is that while one region by measure interaction effect, syntactic comprehension ( $\mathrm{p}=0.003$ ), was significant, the other two effects, semantic category word fluency and expressive agrammatism, only approached significance, not surviving the correction for multiple comparisons $(\mathrm{p}=0.024, \mathrm{p}=0.038$ ). Therefore, these effects should be confirmed by future research. In addition, while LSM is a useful complement to functional neuroimaging, it would help greatly to design fMRI studies carefully enough to obtain significant region by condition interaction effects that can complement the interaction effects obtained here.

Secondarily, while we believe that our measures reflect key aspects of linguistic processing, they can be improved upon and additional research should further develop and refine assessments of different aspects of linguistic processing in people with aphasia. The semantic category word fluency measure was derived from more general test batteries that were not designed to focus on conceptual-semantic processing. Although the existing literature on this measure indicates a strong language component, and a minimal executive function component, it is likely there was at least some executive function contribution to this task. Future research should develop newer, better targeted measures of conceptual-semantic processing that do not involve selection among competing alternatives (as in picture naming) or executive function demands (as in the Pyramids and Palm Trees test). The expressive agrammatism measure was a perceptual rating by experts. Casilio et al. (2019) showed strong concurrent validity between quantitative measures of 
bioRxiv preprint doi: https://doi.org/10.1101/2020.07.17.209262; this version posted April 21, 2021. The copyright holder for this preprint (which

was not certified by peer review) is the author/funder, who has granted bioRxiv a license to display the preprint in perpetuity. It is made available under aCC-BY-NC-ND 4.0 International license.

Functional Differentiation in the Language Network

agrammatism and perceptual ratings of grammatical speech deficits. Our own perceptual ratings of agrammatism had very high inter-rater reliability (Matchin et al., 2020; Den Ouden et al., 2019). Thus, we believe our perceptual ratings are justified. However, it would be useful to complement these perceptual ratings with objective, quantifiable measures that would complement these results. The syntactic comprehension measure, standard in the literature on syntactic comprehension, might involve additional processes beyond syntax such as combinatorial semantics or working memory. While the region by measure interaction effect we showed here indicates a functional dissociation between the function of pMTG and pIFG, it does not necessarily provide knock-down evidence for a strictly syntactic function of pMTG.

Additional measures that seek to isolate syntax from other mechanisms would help to clarify the picture.

Finally, one potential objection to our conclusions regards the possibility of post-stroke functional reorganization. If language is reorganized in the brains of those suffering a stroke to language-relevant regions, as suggested by some authors (Hartwigsen \& Saur, 2019; Stefaniak et al., 2020; Turkeltaub, 2019), how does impact our conclusions? First, to the extent that there is functional organization in post-stroke aphasia, it is likely facilitatory rather than fundamental (e.g. Fridriksson et al., 2012). People with chronic post-stroke aphasia retain significant deficits, and a recent meta-analysis and review of functional neuroimaging studies in people with poststroke aphasia suggesting no evidence of large-scale reorganization (Wilson \& Schneck, 2020). Secondly, functional reorganization would only weaken our ability to detect distinctions across regions, as the impact of a lesion on a given function would be weakened by recovery of function. However, lesion-symptom mapping studies readily identify strong correlations between linguistic deficits and patterns of brain damage, and these findings correspond to what is known from functional neuroimaging (Fridriksson et al., 2018). Crucially, lesion methods are an essential complement to functional neuroimaging in that it helps to identify causal mechanisms of cognition in the brain, both in human and non-human organisms (Lomber et al., 2010; Milner \& Goodale, 1995; Rorden \& Karnath, 2004). Theoretical models of language and the brain were originally developed from the study of aphasia (Wernicke, 1874) and have continue to incorporate its insights (Bornkessel-Schlesewsky \& Schlesewsky, 2013; Friederici, 2002; Hagoort, 2005; Hickok \& Poeppel, 2000, 2004, 2007; Pinker \& Ullman, 2002; Rauschecker \& Scott, 2009). This impact will only be strengthened with improved methods and sample sizes.

\section{Funding \& Acknowledgments}

This research was supported by National Institute on Deafness and Other Communication Disorders grants P50 U01 DC011739 and R01 DC014664 awarded to Julius Fridriksson, and a National Institute on Deafness and Other Communication Disorders grant awarded to Alexandra Basilakos, T32 DC 014435. We would like to thank Grigori Yourganov and Jonathan Venezia for advice on statistical analysis. We would also like to thank Leigh Ann Spell, Allison Croxton, Anna Doyle, Michele Martin, Katie Murphy, and Sara Sayers for their assistance with data collection, and graduate student clinicians in the Aphasia Lab for transcribing and coding speech samples.

\section{Competing Interests}


bioRxiv preprint doi: https://doi.org/10.1101/2020.07.17.209262; this version posted April 21, 2021. The copyright holder for this preprint (which

was not certified by peer review) is the author/funder, who has granted bioRxiv a license to display the preprint in perpetuity. It is made available under aCC-BY-NC-ND 4.0 International license.

Functional Differentiation in the Language Network

The authors declare no competing interests.

\section{References}

Baldo, J. V., Schwartz, S., Wilkins, D., \& Dronkers, N. F. (2006). Role of frontal versus temporal cortex in verbal fluency as revealed by voxel-based lesion symptom mapping. Journal of the International Neuropsychological Society, 12(06). https://doi.org/10.1017/S1355617706061078

Bates, E., Wilson, S. M., Saygin, A. P., Dick, F., Sereno, M. I., Knight, R. T., \& Dronkers, N. F. (2003). Voxel-based lesion-symptom mapping. Nature Neuroscience, 6(5), 448-450. https://doi.org/10.1038/nn1050

Bemis, D. K., \& Pylkkanen, L. (2011). Simple Composition: A Magnetoencephalography Investigation into the Comprehension of Minimal Linguistic Phrases. Journal of Neuroscience, 31(8), 2801-2814. https://doi.org/10.1523/JNEUROSCI.5003-10.2011

Binder, J. R., \& Desai, R. H. (2011). The neurobiology of semantic memory. Trends in Cognitive Sciences, 15(11), 527-536. https://doi.org/10.1016/j.tics.2011.10.001

Binder, J. R., Desai, R. H., Graves, W. W., \& Conant, L. L. (2009). Where Is the Semantic System? A Critical Review and Meta-Analysis of 120 Functional Neuroimaging Studies. Cerebral Cortex, 19(12), 2767-2796. https://doi.org/10.1093/cercor/bhp055

Blank, I. A., \& Fedorenko, E. (2020). No evidence for differences among language regions in their temporal receptive windows. NeuroImage, 219, 116925. https://doi.org/10.1016/j.neuroimage.2020.116925

Blank, I., Balewski, Z., Mahowald, K., \& Fedorenko, E. (2016). Syntactic processing is distributed across the language system. NeuroImage, 127, 307-323. https://doi.org/10.1016/j.neuroimage.2015.11.069

Bornkessel-Schlesewsky, I., \& Schlesewsky, M. (2013). Reconciling time, space and function: A new dorsal-ventral stream model of sentence comprehension. Brain and Language, 125(1), 60-76. https://doi.org/10.1016/j.bandl.2013.01.010

Brennan, J., Nir, Y., Hasson, U., Malach, R., Heeger, D. J., \& Pylkkänen, L. (2012). Syntactic structure building in the anterior temporal lobe during natural story listening. Brain and Language, 120(2), 163-173. https://doi.org/10.1016/j.bandl.2010.04.002

Brennan, J. R., Stabler, E. P., Van Wagenen, S. E., Luh, W.-M., \& Hale, J. T. (2016). Abstract linguistic structure correlates with temporal activity during naturalistic comprehension. Brain and Language, 157-158, 81-94. https://doi.org/10.1016/j.bandl.2016.04.008

Bresnan, J. (2001). Lexical-functional syntax. Blackwell.

Caplan, D., Hildebrandt, N., \& Makris, N. (1996). Location of lesions in stroke patients with deficits in syntactic processing in sentence comprehension. Brain, 119(3), 933-949. https://doi.org/10.1093/brain/119.3.933

Caramazza, A., \& Zurif, E. B. (1976). Dissociation of algorithmic and heuristic processes in language comprehension: Evidence from aphasia. Brain and Language, 3(4), 572-582. https://doi.org/10.1016/0093-934X(76)90048-1

Chertkow, H., \& Bub, D. (1990). Semantic Memory Loss in Dementia of Alzheimer's Type: What do Various Measures Measure? Brain, 113(2), 397-417. https://doi.org/10.1093/brain/113.2.397

Chomsky, N. (1995). The Minimalist Program. MIT Press.

Cohen, J. (1988). Statistical Power Analysis for the Behavioral Sciences. Routledge. 
bioRxiv preprint doi: https://doi.org/10.1101/2020.07.17.209262; this version posted April 21, 2021. The copyright holder for this preprint (which

was not certified by peer review) is the author/funder, who has granted bioRxiv a license to display the preprint in perpetuity. It is made available under aCC-BY-NC-ND 4.0 International license.

Functional Differentiation in the Language Network

Dell, G. S., Schwartz, M. F., Nozari, N., Faseyitan, O., \& Branch Coslett, H. (2013). Voxelbased lesion-parameter mapping: Identifying the neural correlates of a computational model of word production. Cognition, 128(3), 380-396. https://doi.org/10.1016/j.cognition.2013.05.007

Den Ouden, D., Malyutina, S., Basilakos, A., Bonilha, L., Gleichgerrcht, E., Yourganov, G., Hillis, A. E., Hickok, G., Rorden, C., \& Fridriksson, J. (2019). Cortical and structuralconnectivity damage correlated with impaired syntactic processing in aphasia. Human Brain Mapping, 40(7), 2153-2173. https://doi.org/10.1002/hbm.24514

Diachek, E., Blank, I., Siegelman, M., Affourtit, J., \& Fedorenko, E. (2020). The domain-general multiple demand (MD) network does not support core aspects of language comprehension: A large-scale fMRI investigation. The Journal of Neuroscience, JN-RM2036-19. https://doi.org/10.1523/JNEUROSCI.2036-19.2020

Dick, F., Bates, E., Wulfeck, B., Utman, J. A., Dronkers, N., \& Gernsbacher, M. A. (2001). Language deficits, localization, and grammar: Evidence for a distributive model of language breakdown in aphasic patients and neurologically intact individuals. Psychological Review, 108(4), 759-788. https://doi.org/10.1037/0033-295X.108.4.759

Ding, J., Chen, K., Liu, H., Huang, L., Chen, Y., Lv, Y., Yang, Q., Guo, Q., Han, Z., \& Lambon Ralph, Matthew. A. (2020). A unified neurocognitive model of semantics language social behaviour and face recognition in semantic dementia. Nature Communications, 11(1), 2595. https://doi.org/10.1038/s41467-020-16089-9

Ding, N., Melloni, L., Zhang, H., Tian, X., \& Poeppel, D. (2016). Cortical tracking of hierarchical linguistic structures in connected speech. Nature Neuroscience, 19(1), 158164. https://doi.org/10.1038/nn.4186

Dronkers, N. F., Wilkins, D. P., Van Valin, R. D., Redfern, B. B., \& Jaeger, J. J. (2004). Lesion analysis of the brain areas involved in language comprehension. Cognition, 92(1-2), 145-177. https://doi.org/10.1016/j.cognition.2003.11.002

Embick, D., \& Poeppel, D. (2015). Towards a computational(ist) neurobiology of language: Correlational, integrated and explanatory neurolinguistics. Language, Cognition and Neuroscience, 30(4), 357-366. https://doi.org/10.1080/23273798.2014.980750

Faroqi-Shah, Y., \& Milman, L. (2018). Comparison of animal, action and phonemic fluency in aphasia. International Journal of Language \& Communication Disorders, 53(2), 370384. https://doi.org/10.1111/1460-6984.12354

Fedorenko, E., \& Blank, I. A. (2020). Broca's Area Is Not a Natural Kind. Trends in Cognitive Sciences, 24(4), 270-284. https://doi.org/10.1016/j.tics.2020.01.001

Fedorenko, E., Blank, I. A., Siegelman, M., \& Mineroff, Z. (2020). Lack of selectivity for syntax relative to word meanings throughout the language network. Cognition, 203, 104348. https://doi.org/10.1016/j.cognition.2020.104348

Fedorenko, E., Duncan, J., \& Kanwisher, N. (2012). Language-Selective and Domain-General Regions Lie Side by Side within Broca's Area. Current Biology, 22(21), 2059-2062. https://doi.org/10.1016/j.cub.2012.09.011

Fedorenko, E., Nieto-Castañón, A., \& Kanwisher, N. (2012). Syntactic processing in the human brain: What we know, what we don't know, and a suggestion for how to proceed. Brain and Language, 120(2), 187-207. https://doi.org/10.1016/j.bandl.2011.01.001

Fedorenko, E., Nieto-Castañon, A., \& Kanwisher, N. (2012). Lexical and syntactic representations in the brain: An fMRI investigation with multi-voxel pattern analyses. 
Functional Differentiation in the Language Network

Neuropsychologia, 50(4), 499-513.

https://doi.org/10.1016/j.neuropsychologia.2011.09.014

Frank, R. (2002). Phrase structure composition and syntactic dependencies. MIT Press.

Fridriksson, J., den Ouden, D.-B., Hillis, A. E., Hickok, G., Rorden, C., Basilakos, A., Yourganov, G., \& Bonilha, L. (2018). Anatomy of aphasia revisited. Brain, 141(3), 848862. https://doi.org/10.1093/brain/awx363

Fridriksson, J., Richardson, J. D., Fillmore, P., \& Cai, B. (2012). Left hemisphere plasticity and aphasia recovery. NeuroImage, 60(2), 854-863. https://doi.org/10.1016/j.neuroimage.2011.12.057

Friederici, A. D. (2002). Towards a neural basis of auditory sentence processing. Trends in Cognitive Sciences, 6(2), 78-84. https://doi.org/10.1016/S1364-6613(00)01839-8

Friederici, A. D. (2017). Language in our brain: The origins of a uniquely human capacity. MIT Press.

Gallistel, C. R., \& King, A. P. (2010). Memory and the computational brain: Why cognitive science will transform neuroscience. Wiley-Blackwell.

Gleichgerrcht, E., Fridriksson, J., Rorden, C., Nesland, T., Desai, R., \& Bonilha, L. (2016). Separate neural systems support representations for actions and objects during narrative speech in post-stroke aphasia. NeuroImage: Clinical, 10, 140-145. https://doi.org/10.1016/j.nicl.2015.11.013

Goldberg, A. E. (1995). Constructions: A construction grammar approach to argument structure. University of Chicago Press.

Goldberg, A. E. (2003). Constructions: A new theoretical approach to language. Trends in Cognitive Sciences, 7(5), 219-224. https://doi.org/10.1016/S1364-6613(03)00080-9

Goodglass, H., \& Kaplan, E. (1983). Boston Diagnostic Aphasia Examination (BDAE) (2nd ed.). Lippincott Williams \& Wilkins.

Goucha, T., \& Friederici, A. D. (2015). The language skeleton after dissecting meaning: A functional segregation within Broca's Area. NeuroImage, 114, 294-302. https://doi.org/10.1016/j.neuroimage.2015.04.011

Hagoort, P. (2005). On Broca, brain, and binding: A new framework. Trends in Cognitive Sciences, 9(9), 416-423. https://doi.org/10.1016/j.tics.2005.07.004

Hagoort, P. (2014). Nodes and networks in the neural architecture for language: Broca's region and beyond. Current Opinion in Neurobiology, 28, 136-141. https://doi.org/10.1016/j.conb.2014.07.013

Hartwigsen, G., \& Saur, D. (2019). Neuroimaging of stroke recovery from aphasia - Insights into plasticity of the human language network. NeuroImage, 190, 14-31. https://doi.org/10.1016/j.neuroimage.2017.11.056

Heim, I., \& Kratzer, A. (1998). Semantics in Generative Grammar. Wiley-Blackwell.

Hickok, G., \& Poeppel, D. (2000). Towards a functional neuroanatomy of speech perception. Trends in Cognitive Sciences, 4(4), 131-138. https://doi.org/10.1016/S13646613(00)01463-7

Hickok, G., \& Poeppel, D. (2004). Dorsal and ventral streams: A framework for understanding aspects of the functional anatomy of language. Cognition, 92(1-2), 67-99. https://doi.org/10.1016/j.cognition.2003.10.011

Hickok, G., \& Poeppel, D. (2007). The cortical organization of speech processing. Nature Reviews Neuroscience, 8(5), 393-402. https://doi.org/10.1038/nrn2113 
bioRxiv preprint doi: https://doi.org/10.1101/2020.07.17.209262; this version posted April 21, 2021. The copyright holder for this preprint (which

was not certified by peer review) is the author/funder, who has granted bioRxiv a license to display the preprint in perpetuity. It is made available under aCC-BY-NC-ND 4.0 International license.

Functional Differentiation in the Language Network

Hodges, J. R., \& Patterson, K. (2007). Semantic dementia: A unique clinicopathological syndrome. The Lancet Neurology, 6(11), 1004-1014. https://doi.org/10.1016/S14744422(07)70266-1

Hodges, J. R., Patterson, K., Oxbury, S., \& Funnell, E. (1992). Prpgressive fluent aphasia with temporal lobe atrophy. Brain, 115, 1783-1806.

Humphries, C., Binder, J. R., Medler, D. A., \& Liebenthal, E. (2006). Syntactic and Semantic Modulation of Neural Activity during Auditory Sentence Comprehension. Journal of Cognitive Neuroscience, 18(4), 665-679. https://doi.org/10.1162/jocn.2006.18.4.665

Humphries, C., Binder, J. R., Medler, D. A., \& Liebenthal, E. (2007). Time course of semantic processes during sentence comprehension: An fMRI study. NeuroImage, 36(3), 924-932. https://doi.org/10.1016/j.neuroimage.2007.03.059

Humphries, C., Love, T., Swinney, D., \& Hickok, G. (2005). Response of anterior temporal cortex to syntactic and prosodic manipulations during sentence processing. Human Brain Mapping, 26(2), 128-138. https://doi.org/10.1002/hbm.20148

Ivanova, M. V., Herron, T. J., Dronkers, N. F., \& Baldo, J. V. (2021). An empirical comparison of univariate versus multivariate methods for the analysis of brain-behavior mapping.

Human Brain Mapping, 42, 1070-1101.

Jackendoff, R. (2002). Foundations of language: Brain, meaning, grammar, evolution. Oxford University Press.

Joshi, A. K., \& Schabes, Y. (1997). Tree-adjoining grammars. In Handbook of formal languages (pp. 69-123). Springer Berlin.

Kertesz, A. (2007). Western Aphasia Battery-Revised. Grune and Stratton.

Kho, K. H., Indefrey, P., Hagoort, P., van Veelen, C. W. M., van Rijen, P. C., \& Ramsey, N. F. (2008). Unimpaired sentence comprehension after anterior temporal cortex resection. Neuropsychologia, 46(4), 1170-1178. https://doi.org/10.1016/j.neuropsychologia.2007.10.014

Kleist, K. (1914). Aphasie und geisteskrankheit. Münchener Medizinische Wochenschrift, 6, 812.

Kristinsson, S., Thors, H., Yourganov, G., Magnusdottir, S., Hjaltason, H., Stark, B. C., Basilakos, A., den Ouden, D.-B., Bonilha, L., Rorden, C., Hickok, G., Hillis, A., \& Fridriksson, J. (2020). Brain Damage Associated with Impaired Sentence Processing in Acute Aphasia. Journal of Cognitive Neuroscience, 32(2), 256-271. https://doi.org/10.1162/jocn_a_01478

Kussmaul, A. (1877). Die Storungen der Sprache. Vogel.

Lambon Ralph, M. A. (2017). The neural and computational bases of semantic cognition. Nature Reviews Neuroscience, 18, 42-55.

Lau, E. F., Phillips, C., \& Poeppel, D. (2008). A cortical network for semantics: (De)constructing the N400. Nature Reviews Neuroscience, 9(12), 920-933. https://doi.org/10.1038/nrn2532

Lewis, G. A., Poeppel, D., \& Murphy, G. L. (2015). The neural bases of taxonomic and thematic conceptual relations: An MEG study. Neuropsychologia, 68, 176-189. https://doi.org/10.1016/j.neuropsychologia.2015.01.011

Libon, D. J., McMillan, C., Gunawardena, D., Powers, C., Massimo, L., Khan, A., Morgan, B., Farag, C., Richmond, L., Weinstein, J., Moore, P., Coslett, H. B., Chatterjee, A., Aguirre, G., \& Grossman, M. (2009). Neurocognitive contributions to verbal fluency deficits in 
Functional Differentiation in the Language Network

frontotemporal lobar degeneration. Neurology, 73(7), 535-542.

https://doi.org/10.1212/WNL.0b013e3181b2a4f5

Lomber, S. G., Meredith, M. A., \& Kral, A. (2010). Cross-modal plasticity in specific auditory cortices underlies visual compensations in the deaf. Nature Neuroscience, 13(11), 14211427. https://doi.org/10.1038/nn.2653

MacWhinney, B., Fromm, D., Forbes, M., \& Holland, A. (2011). AphasiaBank: Methods for studying discourse. Aphasiology, 25(11), 1286-1307.

https://doi.org/10.1080/02687038.2011.589893

Magnusdottir, S., Fillmore, P., den Ouden, D. B., Hjaltason, H., Rorden, C., Kjartansson, O., Bonilha, L., \& Fridriksson, J. (2013). Damage to left anterior temporal cortex predicts impairment of complex syntactic processing: A lesion-symptom mapping study: ATL Damage Impairs Complex Syntax Processing. Human Brain Mapping, 34(10), 27152723. https://doi.org/10.1002/hbm.22096

Mah, Y.-H., Husain, M., Rees, G., \& Nachev, P. (2014). Human brain lesion-deficit inference remapped. Brain, 137, 2522-1531.

Marczinski, C. A., \& Kertesz, A. (2006). Category and letter fluency in semantic dementia, primary progressive aphasia, and Alzheimer's disease. Brain and Language, 97(3), 258265. https://doi.org/10.1016/j.bandl.2005.11.001

Matchin, W. (2018). A neuronal retuning hypothesis of sentence-specificity in Broca's area. Psychonomic Bulletin \& Review, 25(5), 1682-1694. https://doi.org/10.3758/s13423-0171377-6

Matchin, W., Basilakos, A., Stark, B. C., den Ouden, D.-B., Fridriksson, J., \& Hickok, G. (2020). Agrammatism and paragrammatism: A cortical double dissociation revealed by lesionsymptom mapping. Neurobiology of Language, 1-47. https://doi.org/10.1162/nol_a_00010

Matchin, W., Brodbeck, C., Hammerly, C., \& Lau, E. (2019). The temporal dynamics of structure and content in sentence comprehension: Evidence from fMRI-constrained MEG. Human Brain Mapping, 40(2), 663-678. https://doi.org/10.1002/hbm.24403

Matchin, W., Hammerly, C., \& Lau, E. (2017). The role of the IFG and pSTS in syntactic prediction: Evidence from a parametric study of hierarchical structure in fMRI. Cortex, 88, 106-123. https://doi.org/10.1016/j.cortex.2016.12.010

Matchin, W., \& Hickok, G. (2020). The Cortical Organization of Syntax. Cerebral Cortex, 30(3), 1481-1498.

Matchin, W., \& Wood, E. (2020). Syntax-Sensitive Regions of the Posterior Inferior Frontal Gyrus and the Posterior Temporal Lobe Are Differentially Recruited by Production and Perception. Cerebral Cortex Communications, 1, 1-12. https://doi.org/10.1093/texcom/tgaa029

Mazoyer, B. M., Tzourio, N., Frak, V., Syrota, A., Murayama, N., Levrier, O., Salamon, G., Dehaene, S., Cohen, L., \& Mehler, J. (1993). The Cortical Representation of Speech. Journal of Cognitive Neuroscience, 5(4), 467-479.

Mesulam, M.-M., Thompson, C. K., Weintraub, S., \& Rogalski, E. J. (2015). The Wernicke conundrum and the anatomy of language comprehension in primary progressive aphasia. Brain, 138(8), 2423-2437. https://doi.org/10.1093/brain/awv154

Mesulam, M.-M., Wieneke, C., Hurley, R., Rademaker, A., Thompson, C. K., Weintraub, S., \& Rogalski, E. J. (2013). Words and objects at the tip of the left temporal lobe in primary progressive aphasia. Brain, 136(2), 601-618. https://doi.org/10.1093/brain/aws336 
bioRxiv preprint doi: https://doi.org/10.1101/2020.07.17.209262; this version posted April 21, 2021. The copyright holder for this preprint (which

was not certified by peer review) is the author/funder, who has granted bioRxiv a license to display the preprint in perpetuity. It is made available under aCC-BY-NC-ND 4.0 International license.

Functional Differentiation in the Language Network

Milner, A. D., \& Goodale, M. A. (1995). The visual brain in action. Oxford University Press. Mollica, F., Siegelman, M., Diachek, E., Piantadosi, S. T., Mineroff, Z., Futrell, R., Kean, H., Qian, P., \& Fedorenko, E. (2020). Composition is the Core Driver of the Languageselective Network. Neurobiology of Language, 1(1), 104-134. https://doi.org/10.1162/nol_a_00005

Murphy, E. (2015). The brain dynamics of linguistic computation. Frontiers in Psychology, 6. https://doi.org/10.3389/fpsyg.2015.01515

Nieuwenhuis, S., Forstmann, B. U., \& Wagenmakers, E.-J. (2011). Erroneous analyses of interactions in neuroscience: A problem of significance. Nature Neuroscience, 14(9), 1105-1107. https://doi.org/10.1038/nn.2886

Novick, J. M., Trueswell, J. C., \& Thompson-Schill, S. L. (2005). Cognitive control and parsing: Reexamining the role of Broca's area in sentence comprehension. Cognitive, Affective, \& Behavioral Neuroscience, 5(3), 263-281. https://doi.org/10.3758/CABN.5.3.263

Pallier, C., Devauchelle, A.-D., \& Dehaene, S. (2011). Cortical representation of the constituent structure of sentences. Proceedings of the National Academy of Sciences, 108(6), 25222527. https://doi.org/10.1073/pnas.1018711108

Pick, A. (1913). Die agrammatischen Sprachstorungen. Springer.

Pillay, S. B., Binder, J. R., Humphries, C., Gross, W. L., \& Book, D. S. (2017). Lesion localization of speech comprehension deficits in chronic aphasia. Neurology, 88(10), 970-975. https://doi.org/10.1212/WNL.0000000000003683

Pinker, S., \& Ullman, M. T. (2002). The past and future of the past tense. Trends in Cognitive Sciences, 6(11), 456-463. https://doi.org/10.1016/S1364-6613(02)01990-3

Poeppel, D. (2012). The maps problem and the mapping problem: Two challenges for a cognitive neuroscience of speech and language. Cognitive Neuropsychology, 29(1-2), 34-55. https://doi.org/10.1080/02643294.2012.710600

Poeppel, D., \& Embick, D. (2005). Defining the relation between linguistics and neuroscience. In A. Cutler (Ed.), Twenty-first century psycholinguistics: Four cornerstones (pp. 103-118). Lawrence Erlbaum Associates Publishers.

Poldrack, R. A., Fletcher, P. C., Henson, R. N., Worsley, K. J., Brett, M., \& Nichols, T. E. (2008). Guidelines for reporting an fMRI study. NeuroImage, 40(2), 409-414. https://doi.org/10.1016/j.neuroimage.2007.11.048

Pollard, C., \& Sag, I. (1994). Head-driven phrase structure grammar. University of Chicago Press.

Price, A. R., Bonner, M. F., Peelle, J. E., \& Grossman, M. (2015). Converging Evidence for the Neuroanatomic Basis of Combinatorial Semantics in the Angular Gyrus. Journal of Neuroscience, 35(7), 3276-3284. https://doi.org/10.1523/JNEUROSCI.3446-14.2015

Pylkkänen, L. (2020). Neural basis of basic composition: What we have learned from the redboat studies and their extensions. Philosophical Transactions of the Royal Society B: Biological Sciences, 375(1791), 20190299. https://doi.org/10.1098/rstb.2019.0299

Rauschecker, J. P., \& Scott, S. K. (2009). Maps and streams in the auditory cortex: Nonhuman primates illuminate human speech processing. Nature Neuroscience, 12(6), 718-724. https://doi.org/10.1038/nn.2331

Riccardi, N., Yourganov, G., Rorden, C., Fridriksson, J., \& Desai, R. (2020). Degradation of Praxis Brain Networks and Impaired Comprehension of Manipulable Nouns in Stroke. Journal of Cognitive Neuroscience, 32(3), 467-483. https://doi.org/10.1162/jocn_a_01495 
bioRxiv preprint doi: https://doi.org/10.1101/2020.07.17.209262; this version posted April 21, 2021. The copyright holder for this preprint (which

was not certified by peer review) is the author/funder, who has granted bioRxiv a license to display the preprint in perpetuity. It is made available under aCC-BY-NC-ND 4.0 International license.

Functional Differentiation in the Language Network

Rogalsky, C., \& Hickok, G. (2009). Selective Attention to Semantic and Syntactic Features Modulates Sentence Processing Networks in Anterior Temporal Cortex. Cerebral Cortex, 19(4), 786-796. https://doi.org/10.1093/cercor/bhn126

Rogalsky, C., Rong, F., Saberi, K., \& Hickok, G. (2011). Functional Anatomy of Language and Music Perception: Temporal and Structural Factors Investigated Using Functional Magnetic Resonance Imaging. Journal of Neuroscience, 31(10), 3843-3852. https://doi.org/10.1523/JNEUROSCI.4515-10.2011

Rogalsky, Corianne, LaCroix, A. N., Chen, K.-H., Anderson, S. W., Damasio, H., Love, T., \& Hickok, G. (2018). The Neurobiology of Agrammatic Sentence Comprehension: A Lesion Study. Journal of Cognitive Neuroscience, 30(2), 234-255. https://doi.org/10.1162/jocn_a_01200

Rogers, T. T., Hocking, J., Noppeney, U., Mechelli, A., Gorno-Tempini, M. L., Patterson, K., \& Price, C. J. (2006). Anterior temporal cortex and semantic memory: Reconciling findings from neuropsychology and functional imaging. Cognitive, Affective, \& Behavioral Neuroscience, 6(3), 201-213. https://doi.org/10.3758/CABN.6.3.201

Rorden, C., \& Karnath, H.-O. (2004). Using human brain lesions to infer function: A relic from a past era in the fMRI age? Nature Reviews Neuroscience, 5(10), 812-819. https://doi.org/10.1038/nrn1521

Schwartz, M. F., Kimberg, D. Y., Walker, G. M., Brecher, A., Faseyitan, O. K., Dell, G. S., Mirman, D., \& Coslett, H. B. (2011). Neuroanatomical dissociation for taxonomic and thematic knowledge in the human brain. Proceedings of the National Academy of Sciences, 108(20), 8520-8524. https://doi.org/10.1073/pnas.1014935108

Schwartz, M. F., Kimberg, D. Y., Walker, G. M., Faseyitan, O., Brecher, A., Dell, G. S., \& Coslett, H. B. (2009). Anterior temporal involvement in semantic word retrieval: Voxelbased lesion-symptom mapping evidence from aphasia. Brain, 132(12), 3411-3427. https://doi.org/10.1093/brain/awp284

Stark, B. C., Basilakos, A., Hickok, G., Rorden, C., Bonilha, L., \& Fridriksson, J. (2019). Neural organization of speech production: A lesion-based study of error patterns in connected speech. Cortex, 117, 228-246. https://doi.org/10.1016/j.cortex.2019.02.029

Stefaniak, J. D., Halai, A. D., \& Lambon Ralph, M. A. (2020). The neural and neurocomputational bases of recovery from post-stroke aphasia. Nature Reviews Neurology, 16(1), 43-55. https://doi.org/10.1038/s41582-019-0282-1

Studebaker, G. A. (1985). A "Rationalized" Arcsine Transform. Journal of Speech and Hearing Research, 28(03), 455-462.

Thompson-Schill, S. L., \& Cutler, A. (2005). Dissecting the language organ: A new look at the role of Broca's area in language processing. In Twenty-first century psycholinguistics: Four cornerstones (pp. 173-189). Lawrence Erlbaum Associates Publishers.

Thothathiri, M., Kimberg, D. Y., \& Schwartz, M. F. (2012). The Neural Basis of Reversible Sentence Comprehension: Evidence from Voxel-based Lesion Symptom Mapping in Aphasia. Journal of Cognitive Neuroscience, 24(1), 212-222. https://doi.org/10.1162/jocn_a_00118

Tissot, R., Mounin, G., \& Lhermitte, F. (1973). L'Agrammatisme. Dessart.

Troyer, A. K., Moscovitch, M., \& Winocur, G. (1997). Clustering and Switching as Two Components of Verbal Fluency: Evidence from Younger and Older Healthy Adults. Neuropsychology, 11(1), 138-146. 
bioRxiv preprint doi: https://doi.org/10.1101/2020.07.17.209262; this version posted April 21, 2021. The copyright holder for this preprint (which

was not certified by peer review) is the author/funder, who has granted bioRxiv a license to display the preprint in perpetuity. It is made available under aCC-BY-NC-ND 4.0 International license.

Functional Differentiation in the Language Network

Turkeltaub, P. E. (2019). A Taxonomy of Brain-Behavior Relationships After Stroke. Journal of Speech, Language, and Hearing Research, 62(11), 3907-3922. https://doi.org/10.1044/2019_JSLHR-L-RSNP-19-0032

Tyler, L. K., \& Marslen-Wilson, W. (2008). Fronto-temporal brain systems supporting spoken language comprehension. Philosophical Transactions of the Royal Society B: Biological Sciences, 363(1493), 1037-1054. https://doi.org/10.1098/rstb.2007.2158

Unsworth, N., Spillers, G. J., \& Brewer, G. A. (2011). Variation in verbal fluency: A latent variable analysis of clustering, switching, and overall performance. Quarterly Journal of Experimental Psychology, 64(3), 447-466. https://doi.org/10.1080/17470218.2010.505292

Wernicke, C. (1874). The symptom complex of aphasia: A psychological study on an anatomical basis. In R. S. Cohen \& M. W. Wartofsky (Eds.), Boston studies in the philosophy of science (pp. 34-97). D. Reidel Publishing Company.

Westerlund, M., \& Pylkkänen, L. (2014). The role of the left anterior temporal lobe in semantic composition vs. Semantic memory. Neuropsychologia, 57, 59-70. https://doi.org/10.1016/j.neuropsychologia.2014.03.001

Whiteside, D. M., Kealey, T., Semla, M., Luu, H., Rice, L., Basso, M. R., \& Roper, B. (2016). Verbal Fluency: Language or Executive Function Measure? Applied Neuropsychology: Adult, 23(1), 29-34. https://doi.org/10.1080/23279095.2015.1004574

Wilson, S. M. (2017). Lesion-symptom mapping in the study of spoken language understanding. Language, Cognition and Neuroscience, 32(7), 891-899. https://doi.org/10.1080/23273798.2016.1248984

Wilson, S. M., DeMarco, A. T., Henry, M. L., Gesierich, B., Babiak, M., Mandelli, M. L., Miller, B. L., \& Gorno-Tempini, M. L. (2014). What Role Does the Anterior Temporal Lobe Play in Sentence-level Processing? Neural Correlates of Syntactic Processing in Semantic Variant Primary Progressive Aphasia. Journal of Cognitive Neuroscience, 26(5), 970-985. https://doi.org/10.1162/jocn_a_00550

Wilson, S. M., Dronkers, N. F., Ogar, J. M., Jang, J., Growdon, M. E., Agosta, F., Henry, M. L., Miller, B. L., \& Gorno-Tempini, M. L. (2010). Neural Correlates of Syntactic Processing in the Nonfluent Variant of Primary Progressive Aphasia. Journal of Neuroscience, 30(50), 16845-16854. https://doi.org/10.1523/JNEUROSCI.2547-10.2010

Wilson, S. M., Henry, M. L., Besbris, M., Ogar, J. M., Dronkers, N. F., Jarrold, W., Miller, B. L., \& Gorno-Tempini, M. L. (2010). Connected speech production in three variants of primary progressive aphasia. Brain, 133(7), 2069-2088.

https://doi.org/10.1093/brain/awq129

Wilson, S. M., \& Schneck, S. M. (2020). Neuroplasticity in Post-Stroke Aphasia: A Systematic Review and Meta-Analysis of Functional Imaging Studies of Reorganization of Language Processing. Neurobiology of Language, 2(1), 22-82. https://doi.org/10.1162/nol_a_00025

Zhang, L. (2015). The interplay of composition and concept specificity in the left anterior temporal lobe: An MEG study. NeuroImage, 111, 228-240.

Ziegler, J., \& Pylkkänen, L. (2016). Scalar adjectives and the temporal unfolding of semantic composition_An MEG investigation. Neuropsychologia, 89, 161-171. 